Check for updates

Cite this: Chem. Sci., 2018, 9, 7327

๑ All publication charges for this article have been paid for by the Royal Society of Chemistry

Received 12th May 2018

Accepted 23rd June 2018

DOI: $10.1039 / \mathrm{c} 8 \mathrm{sc0} 02103 a$

rsc.li/chemical-science

\section{Highly diastereoselective synthesis of tricyclic fused-pyrans by sequential hydride shift mediated double $\mathrm{C}\left(\mathrm{sp}^{3}\right)-\mathrm{H}$ bond functionalization $\uparrow$}

\author{
Keiji Mori, (D) ab Nobuaki Umehara ${ }^{a}$ and Takahiko Akiyama (D) *a
}

Described herein is the Brønsted acid-catalyzed double $\mathrm{C}\left(\mathrm{sp}^{3}\right)-\mathrm{H}$ bond functionalization of alkyl phenethyl ether derivatives. In this process, a [1,5]-[1,5]-hydride shift occurred successively to afford tricyclic fused pyran derivatives in excellent chemical yields with excellent diastereoselectivities (up to $>20: 1$ ). The key to achieve this reaction was the introduction of two methyl groups at the benzylic position, which was effective in both hydride shift processes: (1) the Thorpe-Ingold effect for the first hydride shift and (2) conformational control in the second hydride shift.

\section{Introduction}

Development of an efficient synthetic method is a major topic of research interest in modern synthetic organic chemistry. Direct transformation of inert $\mathrm{C}-\mathrm{H}$ bonds, in particular, has attracted much attention because of its high potential for the development of new trends in the synthesis of complex organic molecules. ${ }^{1}$ Hydride shift triggered $\mathrm{C}\left(\mathrm{sp}^{3}\right)-\mathrm{H}$ bond functionalization has recently emerged as a powerful tool for the rapid construction of various useful organic molecules. ${ }^{2}$ Fig. 1 illustrates the details of this strategy. The key feature of this transformation is the $[1,5]$-hydride shift of the $\mathrm{C}\left(\mathrm{sp}^{3}\right)-\mathrm{H}$ bond $\alpha$ to a heteroatom. Subsequent 6-endo cyclization to a cationic species A affords fused heterocycle $2 .^{3-6}$

As part of our ongoing effort to develop a new synthetic transformation method involving hydride shift triggered $\mathrm{C}\left(\mathrm{sp}^{3}\right)-\mathrm{H}$ bond functionalization, ${ }^{7}$ we have recently successfully

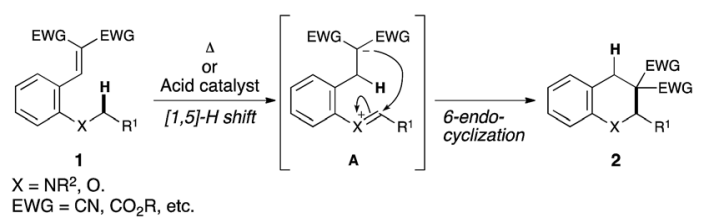

Fig. $1 \mathrm{C}\left(\mathrm{sp}^{3}\right)-\mathrm{H}$ functionalization by the internal redox process.

aDepartment of Chemistry, Faculty of Science, Gakushuin University, 1-5-1 Mejiro, Toshima-ku, Tokyo 171-8588, Japan. E-mail: takahiko.akiyama@gakushuin.ac.jp; Fax: +81-3-3986-1029; Tel: +81-3-3986-0221

${ }^{b}$ Department of Applied Chemistry, Graduate School of Engineering, Tokyo University of Agriculture and Technology, 2-24-16 Nakacho, Koganei, Tokyo 184-8588, Japan $\dagger$ Electronic supplementary information (ESI) available. CCDC 1838259, 1838261 and 1838262. For ESI and crystallographic data in CIF or other electronic format see DOI: $10.1039 / \mathrm{c} 8 \mathrm{sc} 02103 \mathrm{a}$ applied this strategy to a sequential hydride shift system (double $\mathrm{C}\left(\mathrm{sp}^{3}\right)-\mathrm{H}$ bond functionalization). ${ }^{\mathbf{8} 9}$ The key to achieving this reaction was the use of the reactive $\alpha, \beta$-unsaturated trifluoromethyl ketone as the electrophilic moiety. This setting effectively promoted an unprecedented [1,4]-[1,5]hydride shift sequence, affording linear tricyclic piperidines in excellent chemical yields and with excellent diastereoselectivities (eqn (1), Fig. 2). ${ }^{8}$ The application of this sequential system to an oxygen analogue is also highly important because it would be a promising tool for rapid construction of multisubstituted tricyclic pyrans, which are found in some biologically active compounds. The two challenges to achieve this reaction are as follows: (1) the lower electron-donating ability of an oxygen atom than that of a nitrogen atom, which is disadvantageous for the hydride shift process, and (2) the propensity to eliminate the alkoxy group. ${ }^{\mathbf{1 0}}$

We wish to report herein a solution to the issues related to the realization of the double $\mathrm{C}\left(\mathrm{sp}^{3}\right)-\mathrm{H}$ bond functionalization in

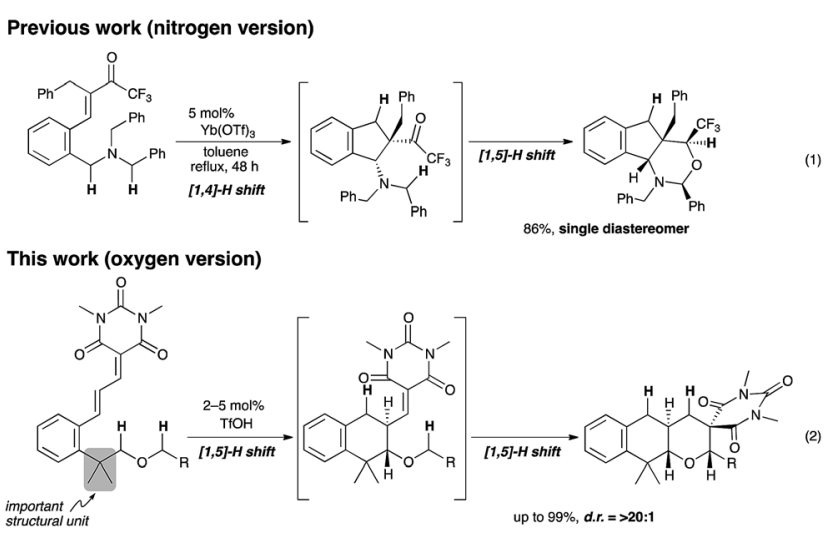

Fig. 2 Double $\mathrm{C}\left(\mathrm{sp}^{3}\right)-\mathrm{H}$ bond functionalization in alkyl phenethyl ether derivatives. 
alkyl phenethyl ether derivatives (eqn (2), Fig. 2). The key to achieving this functionalization was to introduce two methyl groups at the benzylic position, thereby promoting the desired $[1,5]-[1,5]$-hydride shift/cyclization sequence smoothly to furnish the corresponding tricyclic pyrans in excellent chemical yields with excellent diastereoselectivities (up to $>20: 1$ d.r.).

\section{Results and discussion}

An initial trial was conducted with cinnamylidene barbiturate 3 bearing a 2-benzyloxyethyl moiety at the ortho position (Scheme 1). Treatment of 3 with 10 mol\% $\mathrm{Yb}(\mathrm{OTf})_{3}$, which exhibited excellent catalytic performance in the sequential internal redox reactions we previously developed, ${ }^{8,9}$ in refluxing $\mathrm{ClCH}_{2}$ $\mathrm{CH}_{2} \mathrm{Cl}$ resulted in the recovery of the starting material 3. $\mathrm{Gd}(\mathrm{OTf})_{3}$ was also ineffective and the reaction did not proceed at all.

We assumed that these disappointing results were ascribed to the low electron-donating ability of the oxygen atom compared with the nitrogen atom (vide supra). To improve the hydride shift ability, a substrate 5 with a PMP group (electrondonating group $)^{7 c}$ adjacent to the oxygen atom was employed (Scheme 2). Although the starting material 5 was mostly consumed, the resulting product was not the desired adduct $\mathbf{6}$ but the tetracyclic compound 7, which was produced by $\mathrm{BnOH}$ elimination, $E / Z$ isomerization, followed by the inverse electron demand Diels-Alder reaction (IEDDA).

The above results suggest that there are two obstacles to realize the sequential hydride shift reaction: (1) the low reactivity of the substrate and (2) the ease of eliminating the alkoxy

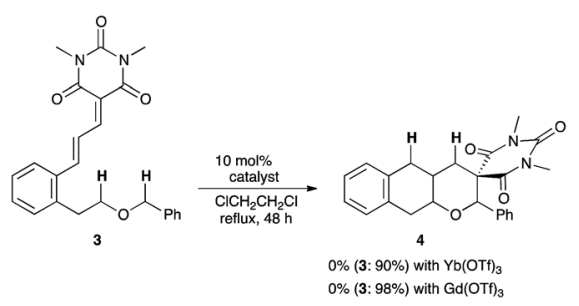

Scheme 1 Initial trial with simple cinnamylidene barbiturate 3 .

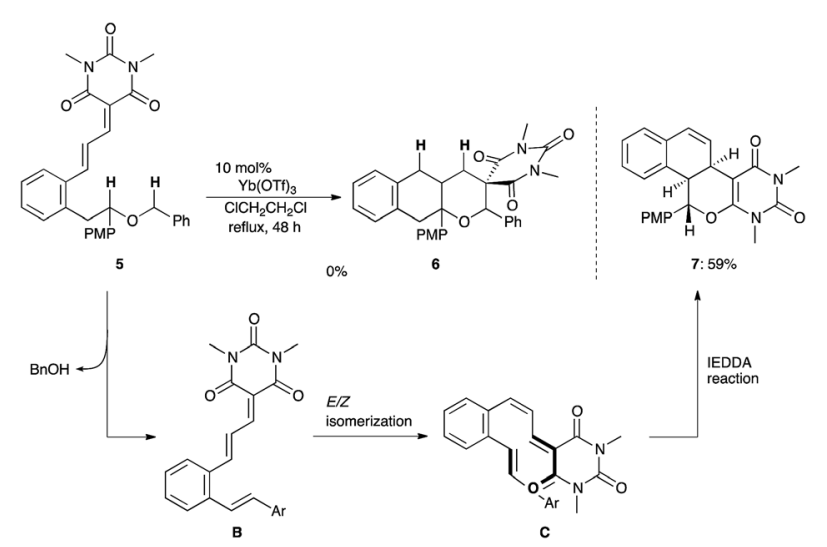

Scheme 2 Reaction of 5 with a PMP group adjacent to the oxygen atom. group. We envisioned that $\mathbf{8}$ with two alkyl groups at the benzylic position would be a suitable substrate for overcoming these issues. This structural modification would be effective in both hydride shift processes (Fig. 3): (1) the Thorpe-Ingold effect for the first hydride shift and (2) the conformational control in the second hydride shift. The cooperative effect of these two factors would lead to a dramatic improvement of the reactivity. Another advantage of using this substrate is the suppression of elimination of the alkoxy group by the absence of benzylic hydrogens.

As expected, the planned reaction proceeded smoothly with 8a. When 8a was treated with $10 \mathrm{~mol} \% \mathrm{Yb}(\mathrm{OTf})_{3}$ in refluxing $\mathrm{ClCH}_{2} \mathrm{CH}_{2} \mathrm{Cl}$, the sequential [1,5]-hydride shift process proceeded to afford the tricyclic pyran derivative 9a in excellent chemical yield (90\%). Only two diastereomers were observed in this reaction even though 9a has three stereogenic centers, and one diastereomer was slightly majored (d.r. = $3.3: 1)$. Other metal triflates such as $\mathrm{Sc}(\mathrm{OTf})_{3}, \mathrm{Gd}(\mathrm{OTf})_{3}$, and Dy(OTf $)_{3}$ also promoted the reaction albeit with lower diastereoselectivities (d.r. $=<4.5: 1$, entries $2-4$ ). The use of $\mathrm{Mg}(\mathrm{OTf})_{2}$ or $\mathrm{TiCl}_{4}$ resulted in the complete recovery of the starting material (entries 5 and 6). $\mathrm{FeCl}_{3}$ promoted the reaction effectively to furnish 9a in 87\% yield with $5.6: 1$ diastereoselectivity (entry 7). $\mathrm{TfOH}$ exhibited high reactivity as well as satisfactory diastereoselectivity ( $86 \%$, d.r. = $13.0: 1$, entry 9$)$, although the reactivity of $\mathrm{Tf}_{2} \mathrm{NH}$, also a strong Brønsted acid catalyst, was moderate $(72 \%$, d.r. $=5.0: 1$, entry 8$) .2 \mathrm{~mol} \%$ TfOH sufficed to complete the reaction with moderate diastereoselectivity (89\%, d.r. $=6.7: 1$, entry 10). Excellent diastereoselectivity was realized even with a $2 \mathrm{~mol} \%$ catalyst when the reaction was conducted in toluene $(99 \%$, d.r. $=>20: 1$, entry 11$)$. The structure of the major diastereomer was determined as described for $9 \mathbf{a}$ by X-ray crystallographic analysis, and those of others shown in Fig. 4 were surmised by analogy. ${ }^{\mathbf{1 1 , 1 2}}$

With the highly diastereoselective tricyclic pyran synthesis in our hand, the substrate scope of this reaction was examined (Fig. 4). ${ }^{13}$ Various substituents such as electron-donating groups (Me and $\mathrm{OMe}$ ) and an electron-withdrawing group (F) were tolerated in this reaction, and the corresponding tricyclic pyrans $\mathbf{9 b}-\mathbf{f}$ were obtained in excellent chemical yields with excellent diastereoselectivities $(>94 \%$, d.r. $=>12.5: 1)$. Although the diastereoselectivity was sufficient (d.r. = 11.2:1),

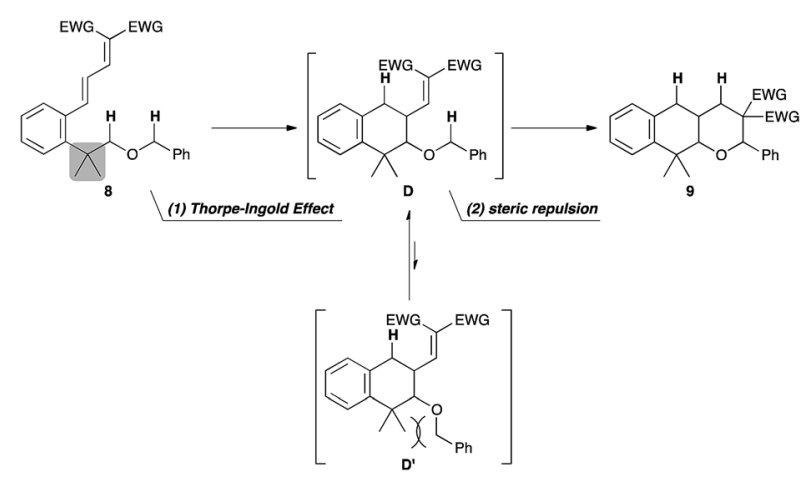

Fig. 3 Design of substrate 8 with a malonate moiety. 


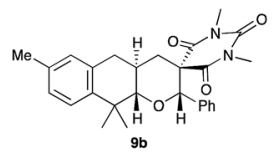

$96 \%, d . r=12.8: 1$

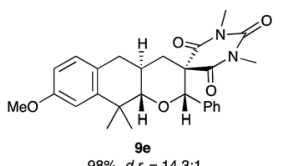

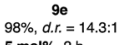

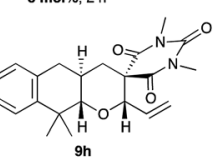

9h

$93 \%, d . r=>20:$
$5 \mathrm{~mol} \%, 24 \mathrm{~h}$

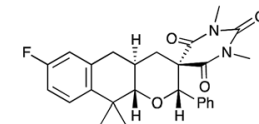

$98 \%, \stackrel{9 c}{9 c}=14.3: 1^{\text {a }}$

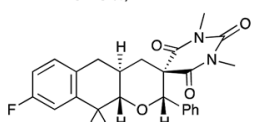

9f

$94 \%, d . r .=19.0 .1$

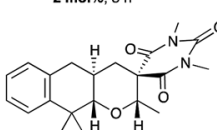

$96 \%, d \cdot r .=>20: 1$

$96 \%, d . r=>20: 1$
$5 \mathrm{~mol} \%, 24 \mathrm{~h}$

a The structure of major diastereomer was determined by $\mathrm{X}$-ray analysis.

Fig. 4 Substrate scope of diastereoselective synthesis of tricyclic pyrans.

the chemical yield was modest (30\%) in the case of the naphthyl substrate $\mathbf{9 g}$ owing to the detachment of the benzyl group. ${ }^{\mathbf{1 4}}$ Both allyl ether $\mathbf{8 h}$ and ethyl ether $\mathbf{8 i}$ were also suitable substrates, and excellent diastereoselectivities were achieved for both substrates (d.r. $=>20: 1$ ). The construction of three contiguous stereogenic centers was also attainable, that is, the reaction of the substrate $\mathbf{8 j}$ with a monomethyl group at the benzylic position afforded the adduct 9 j in 93\% with $3.1: 1$ diastereoselectivity. ${ }^{11}$

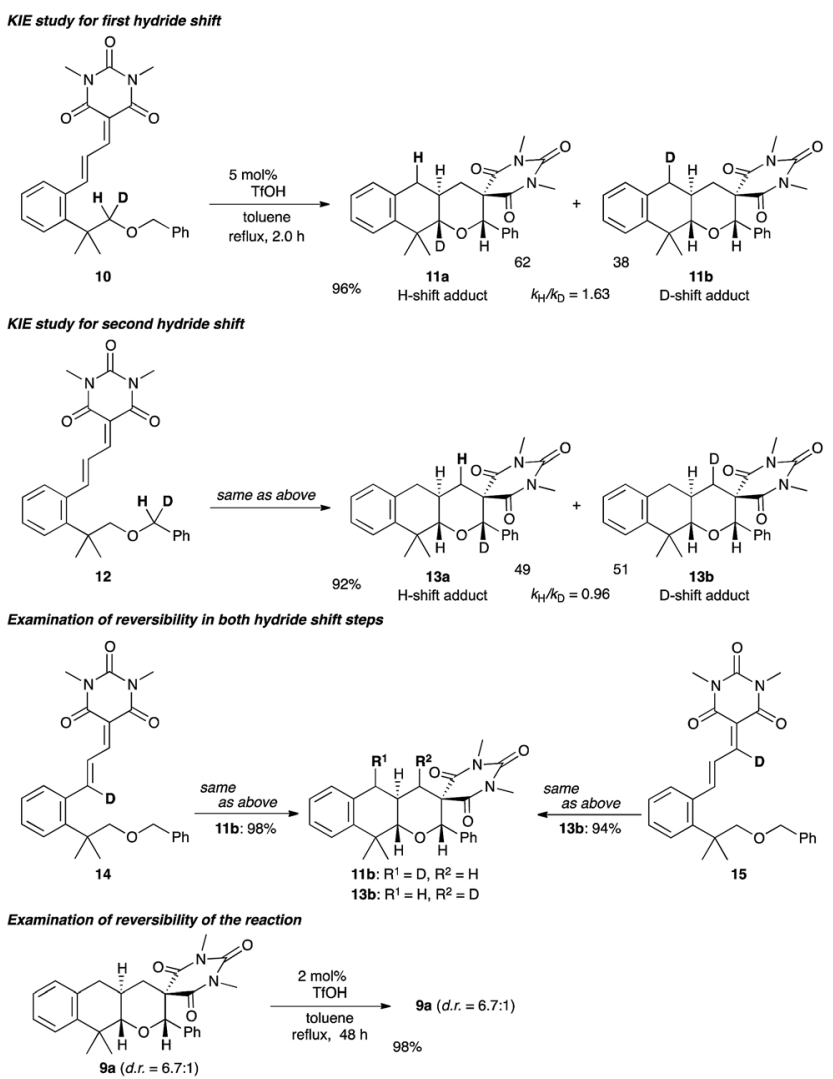

Scheme 3 Additional experiments for clarification of the reaction mechanism.
Table 1 Screening of reaction conditions ${ }^{a}$

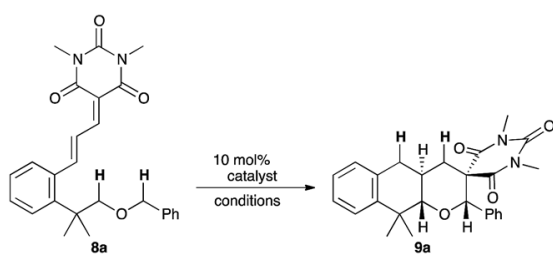

\begin{tabular}{|c|c|c|c|c|}
\hline Entry & Catalyst & Solvent & Yield $^{b}[\%]$ & d.r. ${ }^{c}$ \\
\hline 1 & $\mathrm{Yb}(\mathrm{OTf})_{3}$ & $\mathrm{ClCH}_{2} \mathrm{CH}_{2} \mathrm{Cl}$ & 90 & $3.3: 1$ \\
\hline 2 & $\mathrm{Sc}(\mathrm{OTf})_{3}$ & $\mathrm{ClCH}_{2} \mathrm{CH}_{2} \mathrm{Cl}$ & 88 & $4.2: 1$ \\
\hline 3 & $\mathrm{Gd}(\mathrm{OTf})_{3}$ & $\mathrm{ClCH}_{2} \mathrm{CH}_{2} \mathrm{Cl}$ & $22(68)$ & $2.5: 1$ \\
\hline 4 & $\operatorname{Dy}(\mathrm{OTf})_{3}$ & $\mathrm{ClCH}_{2} \mathrm{CH}_{2} \mathrm{Cl}$ & 60 & $4.5: 1$ \\
\hline 5 & $\mathrm{Mg}(\mathrm{OTf})_{2}$ & $\mathrm{ClCH}_{2} \mathrm{CH}_{2} \mathrm{Cl}$ & $0(98)$ & - \\
\hline 6 & $\mathrm{TiCl}_{4}$ & $\mathrm{ClCH}_{2} \mathrm{CH}_{2} \mathrm{Cl}$ & $0(90)$ & - \\
\hline 7 & $\mathrm{FeCl}_{3}$ & $\mathrm{ClCH}_{2} \mathrm{CH}_{2} \mathrm{Cl}$ & 87 & $5.6: 1$ \\
\hline 8 & $\mathrm{Tf}_{2} \mathrm{NH}$ & $\mathrm{ClCH}_{2} \mathrm{CH}_{2} \mathrm{Cl}$ & 72 & $5.0: 1$ \\
\hline 9 & $\mathrm{TfOH}$ & $\mathrm{ClCH}_{2} \mathrm{CH}_{2} \mathrm{Cl}$ & 86 & $13.0: 1$ \\
\hline $10^{d}$ & $\mathrm{TfOH}$ & $\mathrm{ClCH}_{2} \mathrm{CH}_{2} \mathrm{Cl}$ & 89 & $6.7: 1$ \\
\hline $11^{d, e_{f} f}$ & TfOH & Toluene & 99 & $>20: 1$ \\
\hline
\end{tabular}

${ }^{a}$ Unless otherwise noted, all reactions were conducted with $0.10 \mathrm{mmol}$ of $8 \mathrm{a}$ in the presence of an acid catalyst $(10 \mathrm{~mol} \%)$ in $\mathrm{ClCH}_{2} \mathrm{CH}_{2} \mathrm{Cl}(1.0$ $\mathrm{mL})$ at refluxing temperature. ${ }^{b}$ Isolated yield. ${ }^{c}$ Determined by the comparison of integral values of the C3 (methine) proton of each diastereomer. ${ }^{d}$ MS5 $\AA$ was added. ${ }^{e} 2$ mol\% catalyst. ${ }^{f}$ The reaction was completed within $1 \mathrm{~h}$.

To elucidate the reaction mechanism, additional experiments were conducted (Scheme 3). No primary kinetic isotope effect was observed in both hydride shift processes: The KIE $\left(k_{\mathrm{H} / \mathrm{D}}\right)$ values were determined to be 1.63 (for the first hydride shift) and 0.96 (for the second hydride shift). These results imply the reversibility of both hydride shift processes. To check their possible reversibility, the substrates $\mathbf{1 4}$ and $\mathbf{1 5}$ having the $\mathrm{D}$ atom in vinylic positions were subjected to the optimized reaction conditions. No incorporation of the $\mathrm{D}$ atom into the position adjacent to the oxygen atom was observed, which completely ruled out the reversibility of the hydride shift steps. Furthermore, the diastereomer ratio did not change even when the adduct 9a with low diastereoselectivity (d.r. $=6.7: 1$, entry 10 in Table 1) was subjected to slightly modified optimized reaction conditions ( $2 \mathrm{~mol} \% \mathrm{TfOH}$, toluene, reflux, $48 \mathrm{~h}$ ). Importantly, the relative stereochemistries of the two diastereomers of 9a were determined to be cis and trans in the ring junction $\left[J_{\mathrm{H}-\mathrm{H}}=6.8 \mathrm{~Hz}\right.$ in cis-9a and $J_{\mathrm{H}-\mathrm{H}}=11.6 \mathrm{~Hz}$ in trans-9a (major diastereomer)], which indicates that the diastereoselectivity was determined in the first hydride shift/ cyclization process. The above results suggest that the excellent diastereoselectivities were achieved under kinetic control, and the rate-determining step would be the first cyclization step, and not the hydride shift processes as in the case of the sequential hydride shift system we have recently reported. ${ }^{8}$

\section{Conclusions}

In summary, we have developed a highly diastereoselective synthesis of fused tricyclic pyrans via double $\mathrm{C}\left(\mathrm{sp}^{3}\right)-\mathrm{H}$ bond 
functionalization triggered by sequential hydride shift processes. The key to achieving this goal was the careful design of the substrate with two methyl groups at the benzylic position, and the desired sequential reaction proceeded smoothly with low catalyst loading of $\mathrm{TfOH}$ (only $2 \mathrm{~mol} \%$ ). Various tricyclic pyrans with electron-donating and -withdrawing substituents on the aromatic ring were obtained in excellent chemical yields with excellent diastereoselectivities (up to d.r. $=>20: 1$ ). Additional experiments suggested that the rate-determining step was not the hydride shift step but the first cyclization step. Further investigation on the hydride shift/cyclization sequence, particularly the catalytic asymmetric version, is underway in our laboratory.

\section{Conflicts of interest}

There are no conflicts to declare.

\section{Acknowledgements}

This work was partially supported by a JSPS KAKENHI Grant No. JP26288053 and grants from the Uehara Memorial foundation, Naito foundation, and Inoue Foundation of Science.

\section{Notes and references}

1 For recent reviews on $\mathrm{C}-\mathrm{H}$ activation, see: (a) K. Godula and D. Sames, Science, 2006, 312, 67; (b) R. G. Bergman, Nature, 2007, 446, 391; (c) D. Alberico, M. E. Scott and M. Lautens, Chem. Rev., 2007, 107, 174; (d) H. M. L. Davies and J. R. Manning, Nature, 2008, 451, 417; (e) X. Chen, K. M. Engle, D.-H. Wang and J.-Q. Yu, Angew. Chem., Int. Ed., 2009, 48, 5094; (f) R. Jazzar, J. Hitce, A. Renaudat, J. Sofack-Kreutzer and O. Baudoin, Chem.-Eur. J., 2010, 16, 2654; $(g)$ T. W. Lyons and M. S. Sanford, Chem. Rev., 2010, 110, 1147; $(h)$ H. M. L. Davies, J. Du Bois and J.-Q. Yu, Chem. Soc. Rev., 2011, 40, 1855; (i) T. Brückl, R. D. Baxter, Y. Ishihara and P. S. Baran, Acc. Chem. Res., 2012, 45, 826; (j) Y. Qin, J. Lv and S. Luo, Tetrahedron Lett., 2014, 55, 551; (k) H. M. L. Davies and D. Morton, J. Org. Chem., 2016, 81, 343. See also, highlight on visible-light photocatalysis: X.-Q. Hu, J.-R. Chen and W.-J. Xiao, Angew. Chem., Int. Ed., 2017, 56, 1960.

2 For recent reviews on internal redox process, see: $(a)$ M. Tobisu and N. Chatani, Angew. Chem., Int. Ed., 2006, 45, 1683; (b) S. C. Pan, Beilstein J. Org. Chem., 2012, 8, 1374; (c) M. Wang, ChemCatChem, 2013, 5, 1291; (d) B. Peng and N. Maulide, Chem.-Eur. J., 2013, 19, 13274; (e) L. Wang and J. Xiao, Adv. Synth. Catal., 2014, 356, 1137; $(f)$ M. C. Haibach and D. Seidel, Angew. Chem., Int. Ed., 2014, 53, 5010; (g) S. J. Kwon and D. Y. Kim, Chem. Rec., 2016, 16, 1191.

3 These types of reactions are classified under the term "tertamino effect." For reviews, see: (a) O. Meth-Cohn and H. Suschitzky, Adv. Heterocycl. Chem., 1972, 14, 211; (b) W. Verboom and D. N. Reinhoudt, Recl. Trav. Chim. PaysBas, 1990, 109, 311; (c) O. Meth-Cohn, Adv. Heterocycl.
Chem., 1996, 65, 1; (d) J. M. Quintela, Recent Res. Dev. Org. Chem., 2003, 7, 259; (e) P. Mátyus, O. Elias, P. Tapolcsányi, A. Polonka-Bálint and B. Halász-Dajka, Synthesis, 2006, 2625. 4 For selected examples of internal redox reactions, see: $(a)$ A. Polonka-Bálint, C. Saraceno, K. Ludányi, A. Bényei and P. Mátyus, Synlett, 2008, 2846; (b) C. Zhang, S. Murarka and D. Seidel, J. Org. Chem., 2009, 74, 419; (c) J. C. Ruble, A. R. Hurd, T. A. Johnson, D. A. Sherry, M. R. Barbachyn, P. L. Toogood, G. L. Bundy, D. R. Graber and G. M. Kamilar, J. Am. Chem. Soc., 2009, 131, 3991; (d) M. J. Mahoney, D. T. Moon, J. Hollinger and E. Fillion, Tetrahedron Lett., 2009, 50, 4706; (e) G. Zhou and J. Zhang, Chem. Commun., 2010, 46, 6593; (f) J. Cao, X. Yang, X. Hua, Y. Deng and G. Lai, Org. Lett., 2011, 13, 478; $(g)$ I. D. Jurberg, B. Peng, E. Wöstefeld, M. Wasserloos and N. Maulide, Angew. Chem., Int. Ed., 2012, 51, 1950; (h) T. Sugiishi and H. Nakamura, J. Am. Chem. Soc., 2012, 134, 2504; (i) Y.-Y. Han, W.-Y. Han, X.-M. Zheng and W.-C. Yuan, Org. Lett., 2012, 14, 4054; (j) P. A. Vadpla, I. Carrea and D. Sames, J. Org. Chem., 2012, 77, 6689; $(k)$ X. Gao, V. Gaddam, E. Altenhofer, R. R. Tata, Z. Cai, N. Yongpruksa, A. K. Garimallaprabhakaran and M. Harmata, Angew. Chem., Int. Ed., 2012, 51, 7016; (l) D.-F. Chen, Z.-Y. Han, Y.-P. He, J. Yu and L.-Z. Gong, Angew. Chem., Int. Ed., 2012, 51, 12307; (m) S. Shaaban and N. Maulide, Synlett, 2013, 1722; (n) G. Cera, M. Chiarucci, F. Dosi and M. Bandini, Adv. Synth. Catal., 2013, 335, 2227; (o) A. Dieckmann, M. T. Richers, A. Y. Platonoova, C. Zhang, D. Seidel and N. K. Houk, J. Org. Chem., 2013, 78, 4132; ( $p$ ) M. Alajarin, B. Bonillo, M. Marin-Luna, P. Sanchez-Andrada and A. Vidal, Chem.-Eur. J., 2013, 19, 16093; (q) A. Vidal, M. Martin-Luna and M. Alajarin, Eur. J. Org. Chem., 2014, 878; (r) L. Tóth, Y. Fu, H. Y. Zhang, A. Mándi, K. E. Köver, T.-Z. Iiiyés, A. Kiss-Szikszai, B. Balogh, T. Kurtán, S. Antus and P. Mátyus, Beilstein J. Org. Chem., 2014, 10, 2594; (s) Y.-Z. Chang, M.-L. Li, W.-F. Zhao, X. Wen, H. Sun and Q.-L. Xu, J. Org. Chem., 2015, 80, 9620; $(t)$ C. W. Suh, S. J. Kwon and D. Y. Kim, Org. Lett., 2017, 19, 1334; (u) S.-S. Li, L. Zhou, L. Wang, H. Zhao, L. Yu and J. Xiao, Org. Lett., 2018, 20, 138.

5 For other types of internal redox reactions, see: (a) N. K. Pahadi, M. Paley, R. Jana, S. R. Waetzig and J. A. Tunge, J. Am. Chem. Soc., 2009, 131, 16626; (b) C. Zhang and D. Seidel, J. Am. Chem. Soc., 2010, 132, 1798; (c) I. Deb and D. Seidel, Tetrahedron Lett., 2010, 51, 2945; (d) C. Zhang, D. Das and D. Seidel, Chem. Sci., 2011, 2, 233; (e) H. Mao, R. Xu, J. Wan, Z. Jiang, C. Sun and Y. Pan, Chem.-Eur. J., 2010, 16, 13352; $(f)$ I. Deb, D. Das and D. Seidel, Org. Lett., 2011, 13, 812; $(g)$ H. Mao, S. Wang, P. Yu, H. Lv, R. Xu and Y. Pan, J. Org. Chem., 2011, 76, 1167; (h) D. Das, M. T. Richers, L. Ma and D. Seidel, Org. Lett., 2011, 13, 6584; (i) L. Ma, W. Chen and D. Seidel, J. Am. Chem. Soc., 2012, 134, 15305; (j) D. Das, A. X. Sun and D. Seidel, Angew. Chem., Int. Ed., 2013, 52, 3765; (k) D. Das and D. Seidel, Org. Lett., 2013, 15, 4358; (l) Q.-H. Zheng, W. Meng, G.-J. Jiang and Z.-X. Yu, Org. Lett., 2013, 15, 5298; (m) W. Chen, Y. K. Kang, R. G. Wilde and 
D. Seidel, Angew. Chem., Int. Ed., 2014, 53, 5179; (n) M. T. Richers, M. Breugst, A. Yu, A. Ullrich, A. Dieckmann, K. N. Houk and D. Seidel, J. Am. Chem. Soc., 2014, 136, 6123; (o) Y. Kang, W. Chen, M. Breugst and D. Seidel, J. Org. Chem., 2015, 80, 9628; (p) L. Ma and D. Seidel, Chem.Eur. J., 2015, 21, 12908.

6 For examples of enantioselective internal redox reactions, see: (a) S. Murarka, I. Deb, C. Zhang and D. Seidel, J. Am. Chem. Soc., 2009, 131, 13226; (b) Y. K. Kang, S. M. Kim and D. Y. Kim, J. Am. Chem. Soc., 2010, 132, 11847; (c) W. Cao, X. Liu, W. Wang, L. Lin and X. Feng, Org. Lett., 2011, 13, 600; (d) G. Zhou, F. Liu and J. Zhang, Chem.-Eur. J., 2011, 17, 3101; (e) Y.-P. He, Y.-L. Du, S.-W. Luo and L. Z. Gong, Tetrahedron Lett., 2011, 52, 7064; $(f)$ L. Chen, L. Zhang, Z. Lv, J.-P. Cheng and S. Luo, Chem.-Eur. J., 2012, 18, 8891; (g) L. Zhang, L. Chen, Z. Lv, J.-P. Cheng and S. Luo, Chem.Asian J., 2012, 7, 2569; (h) Z.-W. Jiao, S.-Y. Zhang, C. He, Y.-Q. Tu, S.-H. Wang, F.-M. Zhang, Y.-Q. Zhang and H. Li, Angew. Chem., Int. Ed., 2012, 51, 8811; ( $i$ ) Y. K. Kang and D. Y. Kim, Adv. Synth. Catal., 2013, 355, 3131; (j) C. W. Suh, S. B. Woo and D. Y. Kim, Asian J. Org. Chem., 2014, 3, 399; (k) Y. K. Kang and D. Y. Kim, Chem. Commun., 2014, 50, 222; (l) C. W. Suh and D. Y. Kim, Org. Lett., 2014, 16, 5374; $(m)$ J. Yu, N. Li, D.-F. Chen and S.-W. Luo, Tetrahedron Lett., 2014, 55, 2859; (n) W. Cao, X. Liu, J. Guo, L. Lin and X. Feng, Chem.-Eur. J., 2015, 21, 1632. See also, ref. 7 .

7 For the internal redox reaction developed by our group, see: (a) K. Mori, Y. Ohshima, K. Ehara and T. Akiyama, Chem. Lett., 2009, 38, 524; (b) K. Mori, T. Kawasaki, S. Sueoka and T. Akiyama, Org. Lett., 2010, 12, 1732; (c) K. Mori, S. Sueoka and T. Akiyama, J. Am. Chem. Soc., 2011, 133, 2424; (d) K. Mori, S. Sueoka and T. Akiyama, Chem. Lett., 2011, 40, 1386; (e) K. Mori, T. Kawasaki and T. Akiyama, Org. Lett., 2012, 14, 1436; $(f)$ K. Mori, K. Kurihara and T. Akiyama, Chem. Commun., 2014, 50, 3729; (g) K. Mori, N. Umehara and T. Akiyama, Adv. Synth. Catal., 2015, 357, 901; (h) T. Yoshida and K. Mori, Chem. Commun., 2017, 53, 4319; (i) M. Machida and K. Mori, Chem. Lett., 2018, 47, 868; (j) K. Yokoo and K. Mori, Chem. Commun., 2018, 54, 6927. For an asymmetric version of internal redox reaction catalyzed by chiral phosphoric acid, see: (k) K. Mori, K. Ehara, K. Kurihara and T. Akiyama, J. Am. Chem. Soc., 2011, 133, 6166.

8 K. Mori, K. Kurihara, S. Yabe, M. Yamanaka and T. Akiyama, J. Am. Chem. Soc., 2014, 136, 3744. See, also: L. Wang, J. Xiao, Org. Chem. Front. 2016, 3, 635.

9 Asymmetric version of double $\mathrm{C}\left(\mathrm{sp}^{3}\right)-\mathrm{H}$ bond functionalization: K. Mori, R. Isogai, Y. Kamei,
M. Yamanaka and T. Akiyama, J. Am. Chem. Soc., 2018, 140, 6203.

10 Internal redox reaction of oxygen analogue, see: $(a)$ S. J. Pastine, K. M. McQuaid and D. Sames, J. Am. Chem. Soc., 2005, 127, 12180; (b) S. J. Pastine and D. Sames, Org. Lett., 2005, 7, 5429; (c) K. M. McQuaid and D. Sames, J. Am. Chem. Soc., 2009, 131, 402; (d) D. Shinkai, H. Murase, T. Hata and H. Urabe, J. Am. Chem. Soc., 2009, 131, 3166; (e) P. A. Vadola and D. Sames, J. Am. Chem. Soc., 2009, 131, 16525. See also, ref. $6 h$ and $7 b$.

11 The structures of $\mathbf{9 a}, \mathbf{9 c}$, and $\mathbf{9 j}$ were unambiguously established by single-crystal X-ray analysis. CCDC-1838261, 1838259, and 1838262 contains the supplementary crystallographic data of $\mathbf{9 a}, \mathbf{9 c}$, and $\mathbf{9 j}$.

12 The employment of barbituric acid moiety as an electrophilic portion was critical for the excellent results. The substrates with dimethyl malonate and 1,3cyclohexanedione underwent the desired reactions smoothly to afford the tricyclic compounds, but their diastereomer ratio remained low to moderate (less than d.r. $=<3.6: 1)$.

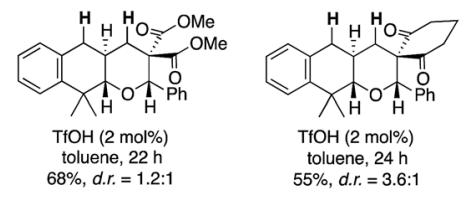

13 All of cinnamylidene barbiturates 8 were used as a mixture of $E / Z$ isomer $(E / Z=>4.3 / 1)$.

14 The low chemical yield of $\mathbf{9 g}$ was ascribed to the formation of 16 (58\%), which was produced via cleavage of benzyl group, intramolecular Michael addition of oxygen atom followed by intramolecular Friedel-Crafts reaction.

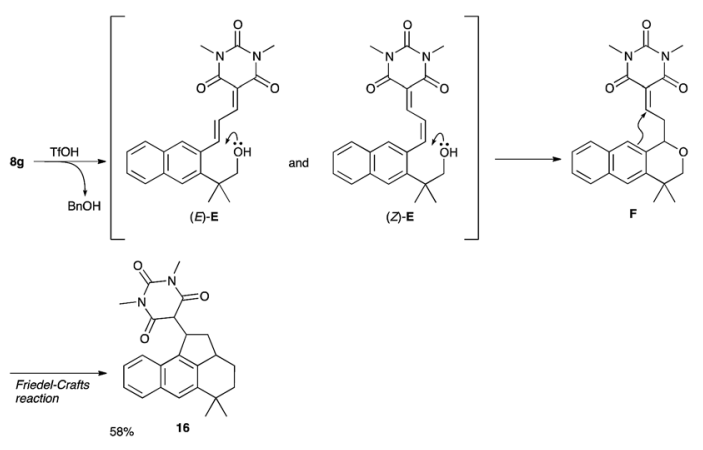

